\title{
A CIDADE, AS VERTENTES E AS VÁRZEAS: A TRANSFORMAÇÃO DO RELEVO PELA AÇÃO DO HOMEM NO MUNICÍPIO DE SÃO PAULO
}

\author{
Alex Ubiratan Goossens Peloggia
}

\begin{abstract}
Resumo: Na presente exposição discutimos a ação do homem nas formas de relevo, especificamente aquela ocorrida no Município de São Paulo. Para tanto, procuramos, em primeiro lugar, expor um arcabouço conceitual preliminar e geral (que foi denominado teoria do relevo tecnogênico) acerca da modificação e criação de processos geomórficos e formas de relevo pelo homem. A partir daí procuramos esboçar um quadro amplo da evolução e das características da morfotecnogênese na região considerada, configurando a superposição de um quadro geomorfológico novo ao sítio urbano original. Por fim, alertamos para a importância da aplicação de tais conceitos na análise e na proposição de formas de resolução dos problemas da ocupação urbana.
\end{abstract}

Palavras-chave: Relevo tecnogênico, Ação humana, Cidade de São Paulo.

\section{Introdução: considerações sobre o estudo do relevo tecnogênico}

A ação do homem na transformação da fisiografia das paisagens, com a criação de um modelado especial correspondente (o relevo tecnogênico) é, juntamente com a influência humana na fisiologia das paisagens (criação $e$ modificação de processos geológicos superficiais) e na criação de depósitos sedimentares correlativos (estratigrafia), uma das três facetas fundamentais do processo que denomina-se geotecnogênese: a transformação do ambiente geológico pelo homem.

$E$, de fato, um dos aspectos mais significativos - e certamente 0 mais evidente - da ação do homem sobre a superfície da Terra é a modificação do relevo. Essa ação especificamente geomorfológica, assim considerada, aparece como a expressão resultante da modificação ou neocriação de processos morfoesculturais (erosivos) e de seus depósitos correlativos, sendo, portanto, uma das marcas características do período Tecnógeno. 0 termo Tecnógeno é usado para se referir a situação geológico-geomorfológica atual, em que a ação geológica humana ganha destaque significativo, no que tange aos processos da dinâmica externa, em relação a processualidade anteriormente vigente (holocênica) (ver, para considerações mais detalhadas, por exemplo: PELOGGIA, 1999; PELOGGIA, 2003, OLIVEIRA et al., 2005; PELOGGIA e
OLIVEIRA, 2005). Assim, o Tecnógeno aparece como expressão geológica da transformação ambiental global, e seu estudo representa uma contribuição original das geociências no entendimento e enfrentamento da crise ambiental contemporânea.

0 estudo dos processos e depósitos tecnogênicos já tem sido alvo de investigações mais aprofundadas. No caso dos processos, é antigo 0 interesse pelos fenômenos de erosão acelerada. 0 interesse pelos depósitos correlativos a tais processos, embora clássico na geologia (aparece nas obras de Charles LYELL e Eduard SUESS, por exemplo; apud PELOGGIA 2005), só mais recentemente foi reavivado. Quanto a caracterização e sistematização mais aprofundadas da ação humana na modificação do relevo, todavia, muito ainda está por fazer.

$O$ próprio Charles LYELL (1997), em Principles of Geology, embora de fato considerasse a ação humana insignificante em relação às forças naturais (e pelo menos até as últimas edições de seu famoso livro), refere-se aos trabalhos humanos relacionados à drenagem de lagos e pântanos e às conseqüências dos desflorestamentos extensivos em regiões montanhosas, como os Alpes, na geração de cargas sedimentares que vão modificar as planícies e linhas costeiras. Desta forma, a ação humana na transformação da geografia física, para LYELL, seja direta ou indireta, tenderia em geral a diminuir as desigualdades da superfície terrestre. Para ele, o homem é, assim, em termos eminentemente geomorfológicos, "um agente nivelador" (levelling agent). 
A preocupação com a caracterização da ação geomorfológica humana pode ser vista, por exemplo, nos trabalhos de Andrew GOUDIE (1994) e Claudio VITA-FINZI (1993). GOUDIE, na obra The Human Impact on the Natural Environment, dedica um capítulo específico ao tema, diferenciando as formas produzidas por "processos antropogênicos diretos" (de aterramento, escavação ou interferência hidrológica, como a retificação geométrica de canais fluviais) e por "processos antropogênicos indiretos" (relacionados a aceleração da erosão e sedimentação, subsidências, escorregamentos em geral, etc.). 0 trabalho de VITA-FINZI, Physiographic Effects of Man (um verbete da Encyclopedia Britannica), por sua vez, também concorda com a separação básica entre, por um lado, mudanças fisiográficas diretas promovidas pela ação humana e, por outro, a contribuição para o desenvolvimento de feições topográficas pela influência humana na ação de outros agentes (erosão acelerada, etc.). 0 autor citado, tal como GOUDIE, preocupa-se em discutir a história da ação geomorfológica humana (que, pode-se dizer, começa com o domínio do fogo e intensifica-se com os processos civilizatórios decorrentes da Revolução Neolítica, que em termos geológicos marcam 0 início do Tecnógeno) e fornecer dados quantitativos acerca da mobilização de materiais pela ação humana. Sabe-se também que pesquisadores soviéticos, na década de 1970, apresentaram uma abordagem sobre o tema (discutida na revista Soviet Geography), porém, o acesso a tal literatura é dificultado em função da ausência dos volumes do período em nossos acervos bibliográficos, fato certamente devido à conjuntura política da época.

Merece ser comentado também o interesse suscitado pelo tema por meio da grande imprensa, com a publicação, no Jornal Folha de S. Paulo de 27 de março de 2005 (caderno Mais!, p.9), da matéria intitulada " $\mathrm{Eu}$, tatu: estudo mostra que seres humanos já são o principal agente causador de erosão na superfície da Terra", assinada pelo editor de ciência Cláudio Ângelo. 0 artigo comenta um estudo do geólogo norte-americano Bruce WILKINSON, da Universidade de Michigan, publicado na revista Geology (WILKINSON, 2005) destacando a importância no que diz respeito à quantificação da ação dos humanos como agentes geológicos, 0 que possibilita sua comparação com a ação de agentes naturais. De fato, WILKINSON conclui que a ação humana tem uma ordem de magnitude mais importante, no que diz respeito à movimentação de sedimentos, do que a soma de todos os outros processos naturais atuantes na superfície do planeta. Seja como for, a matéria jornalística refere-se ainda aos trabalhos de Roger HOOKE, da Universidade do Maine, sobre a história dos seres humanos como agentes geomórficos. 0 autor citado, de fato, considera que 0 homem é um agente geomórfico comparável ou de maior intensidade que qualquer outro e, que desde o Paleolítico vem progressivamente se tornando o principal elemento da esculturação das paisagens (HOOKE, 1994, 2000). Infelizmente, o jornal deixou de se referir aos estudos sobre o tema que vêm sendo realizados no país.

De fato, entre os pesquisadores brasileiros a importância da consideração da influência das atividades humanas na superfície terrestre foi destacada por Antonio CHRISTOFOLETTI (1967), em resenha intitulada "A ação antrópica", em que 0 autor comenta a obra Man's role in changing the face of the Earth, editada por William Thomas Jr e cuja primeira edição foi publicada em 1956. CHRISTOFOLETTI destaca a necessidade da consideração, pelas pesquisas geomorfológicas, das "nuances que os processos assumem frente à ação humana", e de suas conseqüências freqüentemente desastrosas. Especificamente no que diz respeito à consideração das conseqüências geomorfológicas da ação do homem na região de São Paulo, tema tratado aqui, merecem destaque os trabalhos de Adilson A. de ABREU (1986, 1992). Todavia, a preocupação com a proposição de um estudo sistemático e metodologicamente definido da ação geomorfológica humana tem se verificado bem mais recentemente, por exemplo, no trabalho de RODRIGUES (1999), no qual a autora propõe um conjunto de procedimentos metodológicos que denomina "Antropogeomor-fologia", e que consistiriam na consideração das ações humanas especificamente geomorfológicas, na investigação de padrões de ação humana significativos para a morfodinâmica, na investigação histórica das intervenções humanas (tendo em vista sua cumulatividade), no uso de escalas espaço-temporais suplementares (o raciocínio geográfico multiescalar, diríamos) e da cartografia geomorfológica de detalhe, bem como da consideração dos conceitos de limiares, magnitude e freqüência e da análise integrada de sistemas naturais. Um exemplo da utilização de tais procedimentos é exposto no trabalho de LIMA e COLTRINARI (1991), Anthropogenic Changes in a Urban Tropical Landscape: São Paulo (Brazi). Na obra 0 Homem e o Ambiente Geológico (PELOGGIA, 1998a), por outro lado, insere-se o estudo da ação geomorfológica humana (modificação do relevo e dos processos morfoesculturais) como um aspecto da ação geológica do homem, discutindo-se a questão da taxionomia do relevo tecnogênico (tomando por referência a proposta de ROSS, 1992) e das escalas de representação cartográficas. Citou-se também em FANNING e FANNING (1989) as "superfícies decapadas" (scalped land surfaces), as paisagens resultantes da ação do homem como agente geomórfico bem como, usado por ROHDE (1996), a 
expressão "morfotipos artificiais" para se referir a unidades paisagísticas derivadas da ação humana.

\section{Teoria do Relevo Tecnogênico}

Em um trabalho anterior, PELOGGIA (1998b) também procurou discutir alguns aspectos conceituais básicos para 0 estabelecimento do que denominou uma "teoria do relevo tecnogênico". Partiu então da constatação de que a ação morfogenética humana - a criação do relevo tecnogênico - pode se dar de forma tanto direta quanto indireta, e que o homem é um fator tanto de erosão como de deposição, sendo que sua ação, amplamente disseminada pelo planeta, mas não característica de climas particulares, pode aumentar ou diminuir a intensidade das manifestações naturais, como ravinamentos ou inundações.

A ação geomórfica do homem, ou morfotecnogênese, todavia, se dá concretamente sobre situações geológicas prévias, caracterizadas por um arcabouço constituído por formações préquaternárias e por uma estrutura superficial que inclui as porções superiores do regolito, as formações superficiais, os solos "pedogênicos", os depósitos sedimentares não consolidados e, ainda mesmo, os próprios depósitos tecnogênicos. É sobre tal estrutura rasa da paisagem, caracterizada por um certo modelado de relevo e por alguns processos geológicos superficiais (ou de expressão superficial) determinados, inclusive pela ação biológica, em conjunto denominamos de ambiente geológico, que vão ser "esculpidos" os modelados tecnogênicos.

Entendendo aqui os modelados como elementos da paisagem constituídos por conjuntos de formas da superfície terrestre definidos pela ação de um determinado agente ou processo de erosão ou deposição; como na concepção exposta por Jean RISER (1995), podemos caracterizar os modelados tecnogênicos como conjuntos de formas de relevo produzidas direta ou indiretamente pela ação humana (a expressão "paisagens antropogênicas" foi utilizada anteriormente, em sentido semelhante), e que podem ocorrer de maneira conjunta ou associada (o relevo tecnogênico urbano, por exemplo) ou isoladamente. Sendo assim, uma vez que o relevo de uma região pode ter mais de um modelado, que por sua vez constitui-se também de formas taxionomicamente inferiores, o termo relevo tecnogênico abrange um conjunto associado de modelados cujo agente geomórfico é o homem.

A configuração de tais modelados, fruto da ação geomorfológica humana, pode ser abordada em termos da tríade metodológica clássica proposta por AB'SABER $(1968,1969)$ para os estudos do quaternário, ou seja, em termos de processos, depósitos correlativos e formas. Tal método, que adotou-se em estudo anteriores, na verdade condiz com a proposta exposta por RODRIGUES (1999) para a "antropogeomorfologia", qual seja que a consideração das ações humanas como ações geomorfológicas significa considerar que esta atividade promove mudanças nos atributos das formas, nos atributos e posição dos materiais (geológicos) e nas taxas, balanços e vetores dos processos relacionados.

Enfim, uma paisagem qualquer, natural ou não, pode sofrer processos tecnogênicos degradativos (i.e., que implicam na mobilização de material geológico), gerando o que denomina-se formas de primeiro tipo (como terrenos rampados por terraplanagem ou vertentes ravinadas). Os ravinamentos produzidos nas vertentes, que podem produzir corridas de lama, desde que ultrapassados certos limiares de precipitação, são propiciados, como é sabido, pela destruição da cobertura vegetal, a remoção dos solos superficiais ou pela intensificação do escoamento. A alteração das condições hidrológicas, da estrutura superficial da paisagem, dos vetores e limiares de atuação dos processos, nessas circunstâncias, produz formas de relevo tecnogênicas sem a intervenção humana direta na configuração do modelado. A ação direta, por outro lado, normalmente produz por meios mecânicos de escavação geometrias próprias, ou mais ou menos condicionadas pelas superfícies anteriores.

Por outro lado, os processos tecnogênicos também podem implicar na acumulação de material geológico, diretamente por meios mecânicos ou correlativamente à degradação, sendo gerados assim depósitos tecnogênicos que correspondem, em sua expressão geomórfica, a formas de segundo tipo, como os aterros e morrotes artificiais e as planícies aterradas. Materiais carreados das encostas por processos erosivos intensificados, e que vão colmatar a base das vertentes e assorear os canais com "colúvios" e "aluviões", configurarão formas específicas de "rampas" e "terraços" que se enquadram no exemplo discutido.

A ocupação urbana e sua expansão periférica, especificamente, introduzem elementos perturbadores da topografia (expressão de Jean RISER, 1995), ao desenvolver formas de erosão e modelados específicos (como ravinamentos lineares em vias de tráfego não protegidas por pavimentação) decorrentes das formas de ocupação das encostas (que favorecem, ao menos em um primeiro momento, o desequilíbrio das vertentes e a solifluxão) e das várzeas (como a retificação dos canais fluviais e 0 aterramento "em lençol" das planícies). Entre as feições típicas do relevo tecnogênico urbano encontram-se, dentre as formas de primeiro tipo (ou degradativas) aquelas resultantes da ação direta 
(terrenos rampados, submetidos a alterações geométricas por "terraplanagens" de diversos graus, desde as patamarizações de cortes de estabilização até as drásticas "decapagens" de colinas ou morros inteiros) ou, de conseqüências indiretas da ação humana (ou seja, decorrentes da intensificação dos fatores de erosividade).

É interessante notar que se mantém um certo grau de dependência, todavia variável, do relevo tecnogênico em relação ao substrato $\mathrm{e}$ às formas originais. 0 ravinamento produzido em um conjunto de ruas aberto por um certo loteamento, expondo as alteritas de rochas xistosas ou gnáissicas, por exemplo, será mais ou menos intenso em função da relação entre a disposição da rua e a orientação das estruturas planares desses materiais. As antigas áreas de aluviação quaternárias freqüentemente são transformadas em planícies tecnogênicas, que são modelados de segundo tipo, correlacionados a deposição (processo de agradação), e nas quais ocorre a homogeneização da compartimentação anterior (retificação dos canais com padrão arbitrário, geométrico, em lugar dos meandros livres ou divagantes; aterramentos generalizados destruindo os níveis de terraços, diques marginais e brejos inundáveis). Assim, nessas áreas urbanas não existem mais "planícies fluviais quaternárias" (como categoria geomorfológica), conquanto possam restar, via de regra soterrados pelos "terraços antrópicos" (expressão de AB'SABER, 1980), os depósitos aluviais quaternários.

A relação de dependência do modelado tecnogênico às formas e à compartimentação original do relevo implica na consideração da questão taxionômica. Embora a transformação seja drástica, as antigas várzeas em geral continuam a configurar compartimentos relativamente planos e diferenciados em relação aos compartimentos circundantes. No entanto, sua estruturação original, como vimos, não é mais reconhecível (a não ser por algumas curiosas "anomalias" de traçado viário ou de limites de propriedades que seguem antigos traçados de canais fluviais, e que podem ser reconhecidos como relíquias de uma geomorfologia passada). Fica claro que compartimentos como planícies ou conjuntos de colinas ou morros esculpidos sobre um determinado substrato, que representam formas de quarto táxon conforme a classificação de ROSS (1992), conquanto modificados, ainda podem ser reconhecidos como tal, enquanto que as formas menores são obliteradas por um recobrimento quase homogêneo de depósitos tecnogênicos.

De fato, a definição da taxionomia do relevo tecnogênico em relação ao relevo em geral representa uma questão original, uma vez que, no relevo natural temos uma forte ligação genética no encadeamento das formas maiores às menores, as formas de origem humana guardam significativa independência, e mesmo algum condicionamento, eventualmente em relação aos taxons superiores. A ocorrência de morrotes artificiais, frutos de aterramento, em meio a antigas planícies aluviais é um exemplo bastante claro dessa situação. Pode-se considerar, em síntese, que as formas de relevo tecnogênicas se expressam desde a posição inferior (sexto táxon), correspondente a formas menores, até formas de vertentes (quinto táxon) e mesmo, de acordo com a perspectiva, como tipos de formas de relevo individualizadas (correspondentes ao quarto táxon).

\section{0 relevo tecnogênico e a (dupla) originalidade do sítio urbano de São Paulo}

Entre os estudos mais recentes da geologia do Município de São Paulo, e mesmo entre autores que não admitem conceitualmente - e apesar de toda a evidência - 0 advento do Tecnógeno, observa-se a preocupação com 0 estudo da modificação do relevo pelo Homem. RODRIGUEZ (1998), por exemplo, defende que a caracterização da geomorfologia da Região Metropolitana de São Paulo deve abordar dois aspectos fundamentais: por um lado, a configuração geomorfológica natural; de outro, aquela induzida pela urbanização. De fato, já Jean DRESCH (apud PELOGGIA, 1996a, 1998a) alertava que o estudo da transformação das paisagens pelo homem só é autorizado pelo estudo da paisagem natural, somente aí podendo-se passar a uma explicação total, concepção que já foi adotada anteriormente e exposta acima.

Tendo em vista 0 exposto, fica claro que a situação geomorfológica do Município de São Paulo e de sua região metropolitana só pode ser entendida pela imposição de uma reconfiguração parcial do modelado - já fruto dos processos tecnogênicos - sobre um sítio original que mostrava, uma configuração geomorfológica própria. Os limites de tal reconfiguração tecnogênica se dão, portanto, pela conjunção de limites originais impostos pela compartimentação do relevo (especificamente aqui expressas pelas formas de terceiro táxon, como os padrões de colinas da bacia sedimentar e de morros da periferia cristalina) e dos limites dados pela própria capacidade humana de "agir geomorfologicamente" - em função de condicionamentos históricos expressos em termos econômicos, sociais e tecnológicos.

A compartimentação original do relevo paulistano, como se sabe, foi estudada notadamente por Aziz AB'SABER durante décadas, e especificamente numa época em que tal configuração geomorfológica estava prestes a desaparecer quase por completo, 
como resultado de um amplo processo que teve início em meados do século XIX. O próprio AB'SABER (1957), no estudo Geomorfologia do Sítio Urbano de São Paulo, comentava que se pressentia "uma grande transformação nas paisagens antigas das várzeas regionais".

Em síntese, o que se configurava era um núcleo caracterizado por um sistema de colinas esculpidas em camadas terciárias da Bacia Sedimentar de São Paulo, cuja deposição foi fortemente condicionada por basculamentos tectônicos que reativaram antigas estruturas do embasamento pré-cambriano. Tais terrenos antigos do Planalto Paulistano, com a implantação dos processos erosivos pela superimposição da uma nova rede fluvial, vão configurar uma "moldura" aos terrenos terciários, e os processos da fisiologia da paisagem quaternária, controlados pelos efeitos bio-resistáticos da ação climática e, eventualmente, alguma movimentação neotectônica importante, vão determinar a geomorfogênese dos fundos de vale e a escultuação final das colinas circundantes.

A evolução da morfotecnogênese vai se dar do centro para as bordas desse sistema, como descrito em trabalhos anteriores (PELOGGIA, 1996a, 1998a), com a transformação das várzeas centrais (Tamanduateí e Anhangabaú), prosseguindo a jusante para a planície do Tietê e, depois, do Pinheiros e, por fim, dos afluentes desses rios principais em direção às cabeceiras de drenagem. Como comentou AB'SABER (1980), "em raros lugares do mundo tropical duas planícies aluviais meândricas foram tão desfiguradas pela ação humana (...). Ganhou-se uma área enorme de antigos terrenos, transformados em um verdadeiro novo terraço: um nível de terraços antrópicos". Tais terraços, característicos da transformação das várzeas paulistanas, são formas de relevo tecnogênico de primeiro tipo, uma vez que são provenientes principalmente de ações de aterramento que homogeneizaram a topografia ao nível dos antigos terraços de "baixadas relativamente enxutas". Eventualmente, como destacado por RODRIGUEZ (1998), a descaracterização geomorfológica da planície original é mais drástica, como no caso da planície do Rio Grande (um dos formadores do Pinheiros), a jusante da Represa Billings, com a implantação do aterro sanitário de Santo Amaro (morrote artificial).

Concomitante ao processo de aterramento das várzeas principais, a ocupação do sistema de colinas pelos antigos loteamentos mal realizados vai favorecer processos de erosão lineraes (ravinamentos) e formar depósitos de assoreamento nos fundos de vale que hoje freqüentemente jazem inhumados sob 0 leito de grandes avenidas. Fotografias constantes no trabalho de AB'SABER (1958) mostrando tais fenômenos no atual bairro do
Sumaré evidenciam esses processos. Mostram também que os fenômenos de ravinamentos extensivos que se processaram - $\mathrm{e}$ ainda ocorrem - nos terrenos cristalinos das periferias da Bacia Sedimentar apenas repetiram - embora de forma intensificada em função dos fatores de erodibilidade das alteritas dessas rochas e da condição em geral mais precária da ocupação - um padrão histórico social e economicamente determinado.

Ocorre que a progressiva expansão urbana, ao ultrapassar os limites das colinas e antigas planícies, vai apropriar-se de modelados mais agitados, justamente as vertentes mais íngremes sustentadas por terrenos cristalinos (e suas alteritas) que configuram a moldura da Bacia Sedimentar e, geomorfologicamente, constituem divisores de águas locais da bacia de drenagem. Aí a ocupação, ao avançar de forma "remontante" para as cabeceiras das vertentes periféricas, em geral precariamente ocupadas, da metrópole, estabelece uma morfotecnogênese degradativa, marcada por processos particularmente agressivos de erosão linear (ver ABREU, 1986, 1992) e que, paradoxalmente, vai fornecer sedimentos para uma morfotecnogêse agradativa a jusante, ou seja, 0 assoreamento dos vales afluentes dos rios principais. A situação de desequilibrio hidráulico estabelecida - que já foi descrita, em essência, por William Morris DAVIS (1899) em The Geographic Cicle! - promove, por sua vez, a remobilização desse material rio abaixo, em direção justamente às porções mais amplas e tecnogenicamente "estabilizadas" das planícies maiores. Daí porque as intervenções nesses compartimentos (como o alargamento e aprofundamento do canal do Tietê) devem ter sua eficácia hidráulica severamente comprometida enquanto não houver a estabilização morfodinâmica das vertentes e fundos dos vales afluentes.

Por outro lado, é bem verdade que à "crise geomorfológica" (ou "morfogenética", na expressão de ABREU, 1992) resultante do avanço da ocupação urbana, algo que pode ser caracterizado como uma "resistasia antrópica" (na expressão de AB'SABER), segue-se uma estabilização morfodinâmica progressiva, uma vez que os processos erosivos e deposicionais são reduzidos em função da consolidação urbana (o que ROSS, 1991, denominou "estabilidade morfodinâmica antrópica"). 0 que se segue é uma situação de equilibrio dinâmico, caracterizada por alterações significativas no regime hídrico (ver, para tal discussão, por exemplo, o trabalho de ROSS, 2004), mas na qual a nova configuração geomorfológica da paisagem tecnogênica evolui em ritmo bastante lento.

Configura-se assim, uma "neo-originalidade" geomorfológica, herdeira da originalidade do próprio sítio urbano de São Paulo mas definida, essencialmente, pelas formas de apropriação do relevo 
pelo homem.

\section{Considerações finais}

0 que é importante ressaltar, ao fim desta exposição, é que, em extensão significativa, na cidade de São Paulo e seus arredores, assim como em inúmeras outras aglomerações urbanas ao redor do mundo, as planícies aluviais e vertentes recobertas por formações superficiais holocênicas (em termos de suas processualidades originais, como categorias geomorfológicas) não existem mais em significativa extensão (i.e., os processos que formaram os depósitos continentais holocênicos, daquela forma, não são mais atuantes). Existem nesses casos planícies e vertentes tecnogênicas, nas quais o registro sedimentar holocênico (ou eventualmente pleistocênico) se encontra como relíquia. A originalidade da fisiologia das paisagens urbanas é, portanto, que ela é dominada por processos tecnogênicos.

Infelizmente, notou-se nos últimos anos que algumas propostas de aplicação do conhecimento geocientífico para 0 planejamento e a resolução de problemas relacionados com a ocupação urbana vem desconsiderando o "fator humano" e a própria condição diferenciada das paisagens tecnogênicas, em termos de seu funcionamento. É o que se verifica, particularmente, nos trabalhos de "cartografia geotécnica" executados no Município de São Paulo nas décadas de 1980 e 1990, chegando-se a caracterizações tão longe da realidade como a de que as planícies "aluvionares" teriam "baixíssimo potencial erosivo". Na verdade, as planícies tecnogênicas (pois são elas que existem) não têm baixíssimo potencial erosivo, pois há constante remobilização de material por solapamento das margens dos canais, em função da situação de instabilidade hidráulica configurada. A crítica sistemática a tais trabalhos já foi feita, por exemplo, por RODRIGUES (1997) e PELOGGIA (1996a, 1996b, 1998a). 
PELOGGIA, A. U. G. (2005). The city, the slopes and valleys: relief transformation by human action in São Paulo city. Revista do Departamento de Geografia, n. 16, p. 24-31.

Abstract: In this presentation we discuss the human action on relief, specifically in what concerns to São Paulo City. First, we expose a preliminary and general framework (what we call The Technogenic Relief Theory) about the modification and creation of geomorphic processes and relief forms by man. Then we outline a wide picture of the characteristics and evolution of morphogenesis in the studied region, what shapes the superposition of a new geomorphologic condition to the original urban land. At last, we alert for the importance of application of the discussed concepts to the analysis and suggestion of solutions regarding urban occupation problems.

Key words: Technogenic relief; Human action; São Paulo City.

Recebido em 7 de setembro de 2005, aceito em 2 de outubro de 2005.

\section{Referências}

ABREU, A.A. (1986) Ação antrópica e propriedades morfodinâmicas do relevo na área metropolitana de São Paulo. Orientação. Instituto de Geografia, Universidade de São Paulo (7) p. 35-38,

ABREU, A.A. (1992) Do Pátio do Colégio ao Planalto Paulistano: problemas geomorfológicos emergentes do Município de São Paulo. In: Problemas Geológicos e Geotécnicos na Região Metropolitana de São Paulo, São Paulo, ABAS/ABGE/SBG-SP, p. 47-54.

AB'SABER, A.N. (1957) Geomorfologia do sítio urbano de São Paulo. São Paulo, FFLCH/USP, Boletim 219 (Geografia 12). 343p.

AB'SABER, A.N. (1958) 0 sítio urbano de São Paulo. In: AZEVEDO, A. (org.), A Cidade de São Paulo. São Paulo, AGB / Cia. Ed. Nacional. p. 169-245.

AB'SABER, A.N. (1968) Bases geomorfológicas para o estudo do Quaternário do Estado de São Paulo. Tese de Cátedra. FFCL, USP. 299p.

AB'SABER, A.N. (1969) Um conceito de geomorfologia a serviço das pesquisas sobre 0 Quaternário. Geomorfologia 8. Instituto de Geografia, USP. p. 1-15.

AB'SABER, A.N. (1980) Súmula geomorfológica do Planalto Paulistano. In: Aspectos Geológicos e Geotécnicos da Bacia Sedimentar de São Paulo, São Paulo, ABGE / SBG-SP, p.3336.

CHRISTOFOLETTI, A. (1967) A ação antrópica. In: Notícia Geomorfológica 13/14. p. 66-67.

DAVIS, W.M. (1899) The geographycal cycle. Geographycal Journal 14. p. $481-504$.

FANNING, D.J. e FANNING, M.C.B. (1989) Soil: morphology, genesis and classification. New York: John Wiley \& Sons.
GOUDIE, A. (1994) The human impact on the natural environment. 4. ed., Cambridge (Massachusetts). The MIT Press.

HOOKE, R.L. (1994) On the efficacy of humans as geomorphic agents. GSA Today 4(9):217. p. 224-225.

HOOKE, R.L. (2000) On the history of humans as geomorphic agents. Geology 28(9). p. 843-846.

LYELL, C. (1997) Principles of Geology. London: Penguin. 472p, (Texto selecionado da primeira edição inglesa, publicada em Londres, por John Murray, em três volumes, de 1830 a 1833).

LIMA, C.R. e COLTRINARI, L. (1991) Anthropogenic changes in a urban tropical landscape: São Paulo (Brazil). In: INQUA CONGRESS, XIII, Beijing.

OLIVEIRA, A.M.S.; BRANNSTROM, C.; NOLASCO, M.C.; PELOGGIA, A.U.G.; PEIXOTO,M.N.O.; COLTRINARI, L. (2005) Tecnógeno: registros da ação geológica do homem. In: SOUZA, C.R.G. et al. (eds.), Quaternário do Brasil. São Paulo: ABEQUA; Ribeirão Preto: Holos, cap. 17.

PELOGGIA, A. (1996a) Delineação e aprofundamento temático da Geologia do Tecnógeno do Município de São Paulo. São Paulo, (Tese de Doutoramento, Instituto de Geociências da USP).

PELOGGIA, A. (1996b) Discussão sobre a atual cartografia geotécnica do município de São Paulo e suas possíveis aplicações. In: Revista Brasileira de Geociências 26(4). p. 315319.

PELOGGIA, A. (1998a) O Homem e o Ambiente Geológico: geologia, sociedade e ocupação urbana no Município de São Paulo. São Paulo, Xamã. 271p.

PELOGGIA, A. (1998b) A magnitude e a freqüência da ação humana representam uma ruptura na processualidade geológica na superfície terrestre? In: Geosul 14(27). p. 54-60. 
PELOGGIA, A. (1999) O Tecnógeno existe? In: Congresso Brasileiro de Geologia de Engenharia, 9, São Pedro (SP), Anais. ABGE (CD-ROM). 13p.

PELOGGIA, A. (2003) 0 problema estratigráfico dos depósitos tecnogênicos. In: Congresso da Associação Brasileira de Estudos do Quaternário, 9, Recife, Anais. ABEQUA (CDROM). 5p.

PELOGGIA, A. (no prelo) A ação geológica do homem nos clássicos da geologia, com especial atenção aos Principles of Geology de Lyell. In: Congresso da Associação Brasileira de Estudos do Quaternário, 10, Guarapari (ES), Anais. ABEQUA. $6 \mathrm{p}$.

PELOGGIA, A. e OLIVEIRA, A.M.S. (no prelo) Tecnógeno: um novo campo de estudos das Geociências. In: Congresso da Associação Brasileira de Estudos do Quaternário, 10, Guarapari (ES), Anais. ABEQUA, 4p.

RISER, J. (1995) Érosion et paysages naturels. Paris, Flammarion.

RODRIGUES, C. (1999) On Anthropogeomorphology. In:. Regional Conference on Geomorphology, Rio de Janeiro. Anais. Rio de Janeiro, IAG/UGB.

RODRIGUES, C. (1997) Geomorfologia aplicada: avaliação de experiências e de instrumentos de planejamento físico- territorial e ambiental brasileiros. São Paulo, 276p. (Tese de Doutoramento, Faculdade de Filosofia, Letras e Ciências Humanas da USP).

RODRIGUEZ, S.K. (1998) Geologia urbana da Região Metropolitana de São Paulo. São Paulo, (Tese de Doutoramento, Instituto de Geociências da USP). 171p.

ROHDE, G.M. (1996) Epistemologia ambiental. Porto Alegre, Edipucrs. 231p.

ROSS, J.L.S. (1991) Geomorfologia: ambiente e planejamento. 2.ed. São Paulo, Contexto. 85p.

ROSS, J.L.S. (1992) 0 registro cartográfico dos fatos geomórficos e a questão da taxonomia do relevo. In: Revista do Departamento de Geografia 6. FFLCH-USP. p.17-29.

ROSS, J.L.S. (2004) São Paulo: a cidade e as águas. In: CARLOS, A.F.A. e OLIVEIRA, A.U. (orgs.), Geografias de São Paulo v.2, A metrópole do século XXI. São Paulo, Contexto. p.183-219.

VITA-FINZI, C. (1993) Physiographic effects of man. IN: The New Encyclopaedia Britannica, Macropaedia, v.20, 15.ed., Chicago. p. 22-26.

WILKINSON, B.H. (2005) Humans as geologic agents: a deep-time perspective. Geology 33(3). p.161-164. 